Journal of Case Reports 2019;9(1):40-43

\title{
Metastasis of Renal Cell Carcinoma to Mandible
}

\author{
Esra Altunsoy ${ }^{1}$, Ö. Fahrettin Göze ${ }^{2}$, İlker Özeç ${ }^{1}$, Emin Yener Gültekin ${ }^{3}$, Tuğçe Çevik Işıtan ${ }^{1}$ \\ Departments of ${ }^{1}$ Oral and Maxillofacial Surgery, ${ }^{2}$ Pathology and ${ }^{3}$ Urology, Cumhuriyet University, Faculty of Dentistry, Sivas, \\ Turkey.
}

\section{Corresponding Author:}

Dr. Tuğçe Çevik Işıtan

Email: tugcecevik_89@hotmail.com

This is an Open Access article distributed under the terms of the Creative Commons Attribution License (creativecommons.org/ licenses/by/3.0).

Received Accepted

Published

November 24, 2018

January 24, 2019

February 25, 2019

\begin{abstract}
Background: Renal cell carcinoma (RCC) is one of the most common urological malignancies. Case Report: A 62-year-old male patient was admitted to our clinic due to painful swelling on the right side of his face. On the panoramic radiograph, a well defined, unilocular, approximately $1.9 \times 1.5 \mathrm{~cm}$ sized radiolucent area was observed. It was decided to enucleate the lesion, which was thought to be 'radicular cyst' radiographically. While performing incision and flap operations, bleeding continued in an abnormal amount. Surgical material was diagnosed a RCC metastasis. Conclusion: The possibility of a metastatic tumor in cases with excessive bleeding during surgery should be kept in mind.
\end{abstract}

Keywords: Head and Neck Neoplasms, Mandible, Metastasis, Renal cell carcinoma, Radicular Cyst, Panoramic Radiography.

\section{Introduction}

Renal cell carcinoma (RCC) accounts for 3\% of all tumors in adults [1]. RCC is the most common malignant tumor of the kidney (90-95\%) and is usually seen in males between $30-60$ years [2]. It is the third most common infra-clavicular neoplasm that metastasizes to the oral cavity, following that of lung and breast tumors [3]. RCC often spreads to lungs, liver, bones, lymph nodes; rarely metastasizes to the head and neck region [4]. RCC metastasizes to the thyroid, parotid, tonsil, tongue, sinonasal region, mandible and skin in this region [4]. The main symptoms of the metastatic tumors in the oral cavity are swelling, pain, bleeding and tooth loss [4]. In this article, we report a case of metastatic RCC to the mandible.

\section{Case Report}

A 62-years old male patient was admitted to Cumhuriyet University, Faculty of Dentistry, Department of Oral and Maxillofacial Surgery, due to painful swelling on the right side of his face. The current swelling was noticed about two months ago. Antibiotic treatment was advised by different dentists at this period. The patient had diabetes mellitus and hypertension for ten years.

On the panoramic radiograph, a well defined, unilocular, approximately $1,9 \times 1.6 \mathrm{~cm}$ sized radiolucent area extending from the lower right first premolar to the second molar was observed [Fig.1]. It was decided to enucleate the lesion, which was thought to be 'radicular cyst' radiographically, and to extract the second premolar tooth. While performing operation, bleeding continued in an abnormal amount, and enucleation was made very difficult. Bleeding was controlled by dental spongostane (Ferrosan). Bleeding could be stopped with compression in addition to this medical treatment [Fig.2].

$$
\text { İmmunohistocemical (IHC) panel }
$$
consisting of S-100, CD1a, CD34, CD68 and PAN$\mathrm{CK}$ was applied for the differential diagnosis of this clear cell lesion [Fig.3]; only diffuse cytoplasmic positive immunoreactivity with pan-CK was obtained in tumor cells [Fig.4]. Accordingly, 
"epithelial malignant tumor metastasis" and especially RCC metastasis were considered. The pathology archive was scanned. Approximately one year ago, the patient who underwent nephrectomy was diagnosed with "RCC" and showed histopathological similarities with the mandibular mass, and it was concluded that the mandibular mass was metastasis of kidney tumor as well as clear cell RCC [Fig.5,6].

On the whole body scintigraphy, focally prominent increased osteoblastic activity was observed in the right mandibular region. In addition, osteoblastic increased activity was detected in a small focus at the $1 / 3^{\text {rd }}$ distal portion of the right

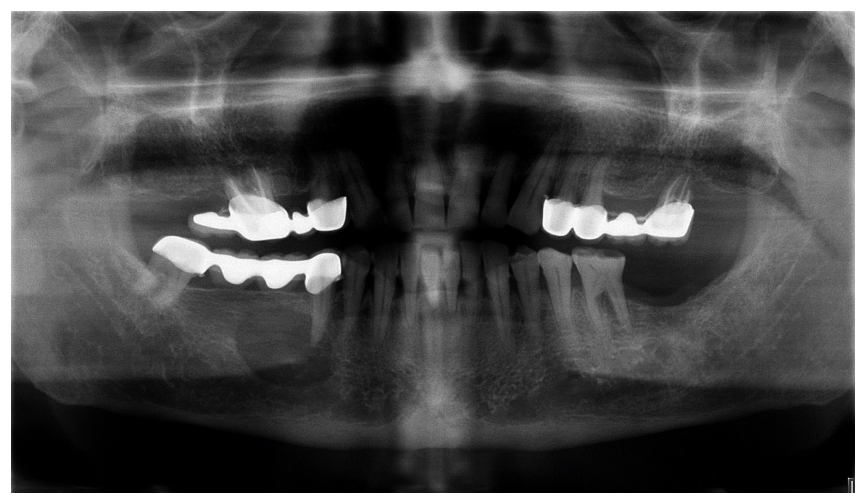

Fig.1: The patient's panoramic radiograph showed a welldefined radiolucent area in the right mandibular premolarmolar region.

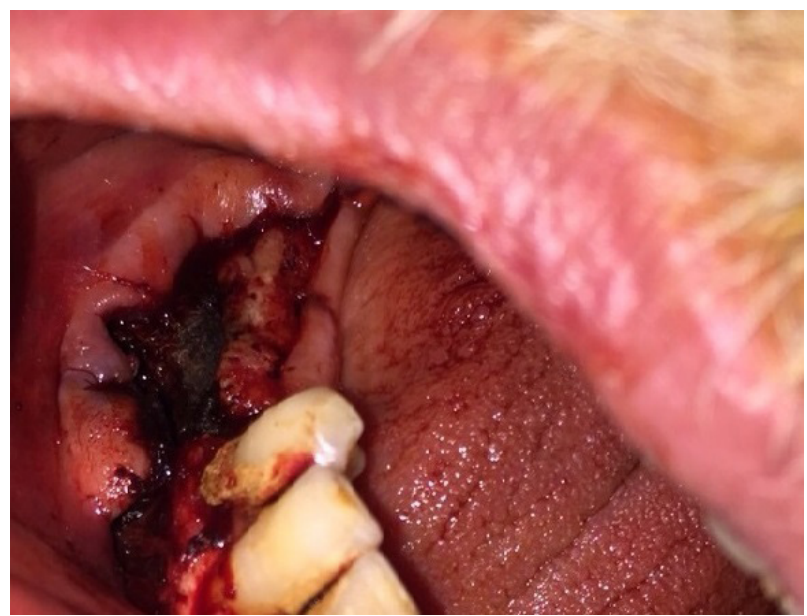

Fig.2: Clinical view of the operation area after the bleeding was controlled with medical treatment and compression. femur and $1 / 3^{\text {rd }}$ proximal portion of the left tibia [Fig.7]. The patient was scheduled for palliative treatment after consulting with the department of oncology following enucleation. The region was healed by rinsing with rifamycin (Rifocin $250 \mathrm{mg}$ / $\mathrm{ml}$ ) for two weeks.

\section{Discussion}

RCC constitutes approximately $3 \%$ of all adulthood tumors [5]. Most cases of RCC occur in individuals aged between 30-60 years [6]. Approximately 75\% of all detected RCCs are clear cell RCCs [7]. RCC

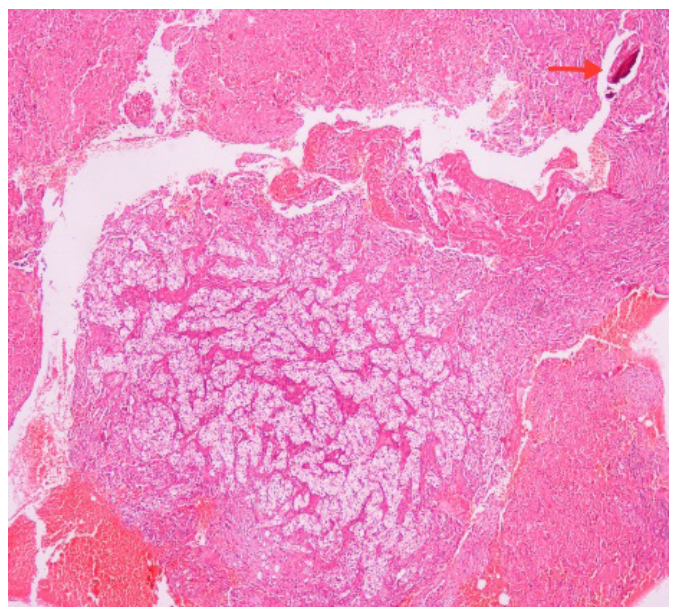

Fig.3: Tumor metastasis to the mandible (red arrow shows small bone spicle) (HE x 40).

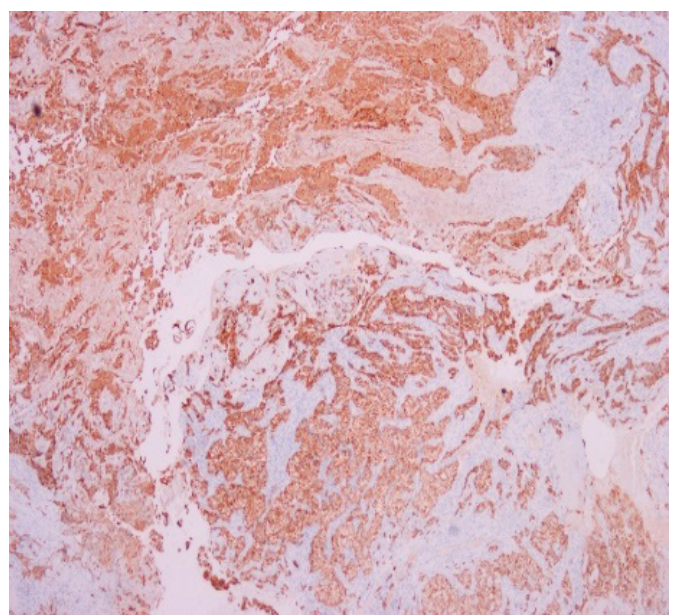

Fig.4: Immunohistochemistry of the lesion in the jawbone. Tumor cells were stained with PAN-CK diffuse cytoplasmic $(I H K \times 40)$. 


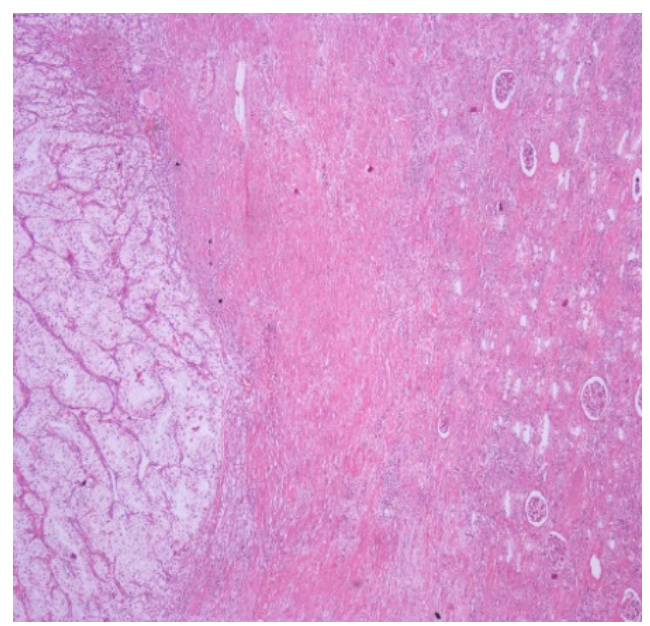

Fig.5: Overview of the primary clear cell tumor (RCC) adjacent to the kidney tissue at the left flank (HEx 40).

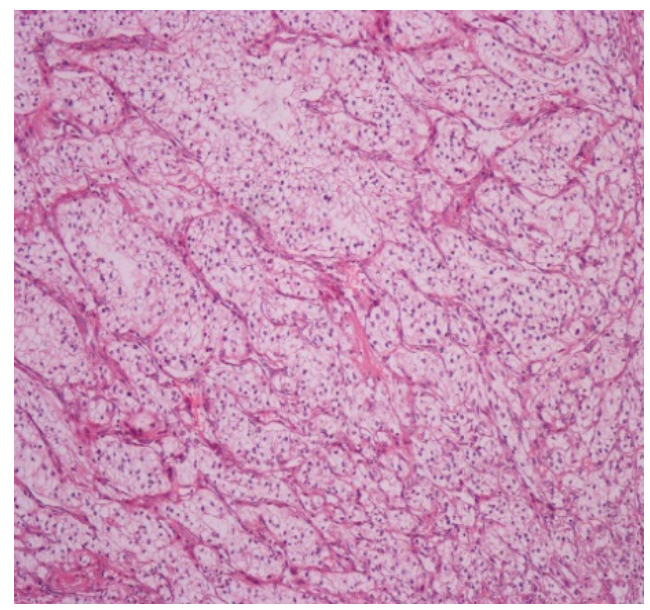

Fig.6: Detailed view of the tumor: tumor cell nests with small hypercellular nuclei in the clear cytoplasm between delicate fibrovascular stroma (HE x100).

metastasizes usually late and its metastasis is seen in $20-40 \%$ of patients [2]. However, some of the cases are diagnosed after metastasis [8]. Metastatic $\mathrm{RCC}$ is known as one of the most resistant tumors to treatment. Average survival rate after diagnosis is less than one year [9]. RCC is known to cause distant metastasis to many tissues and organs [10]. RCC is one of the most common tumors that metastasize to the head and neck region following lung and breast cancer. $15 \%$ of cases metastasize to the head and neck region [11]. The thyroid gland is the most common organ in this region that has undergone metastasis by RCC [12]. Soft tissue

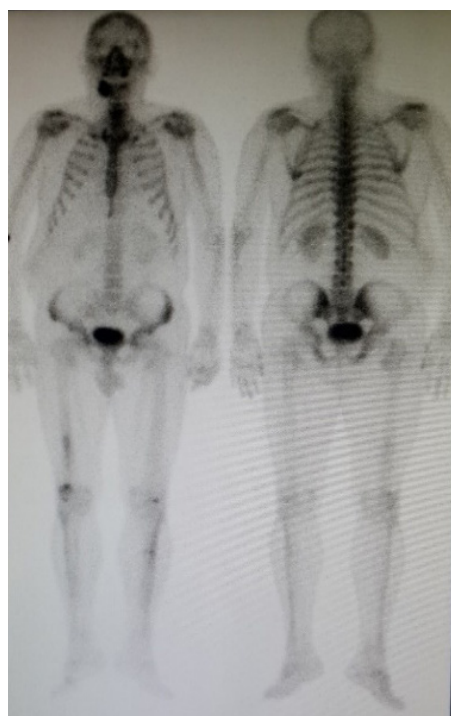

Fig.7: Whole body bone scintigraphy. Osteoblastic increased activity in the right mandibular region, also in a small focus at the 1/3 distal portion of the right femur and 1/3 proximal portion of the left tibia.

metastasis, such as oral gingiva, tongue, uvula and lip, have also been reported $[8,13]$.

The majority of distant metastasis occur within the first two years after definitive treatment of the primary tumor [14]. In our patient, metastasis to the mandible occurred one year after nephrectomy. Mandibular metastasis is usually evidence of extensive spread and has a serious prognosis. The time from the onset of metastasis to death may not be a few months long, and more than two-thirds of patients with metastatic carcinoma in their jaw die within one year. The 4-year survival rate is only about 10\% [15]. We lost also our patient 17 months after mandibular metastasis.

In a differential diagnosis, pyogenic granuloma, bone diseases including osteomyelitis, mandibular cysts, primitive malignant tumors of jaws, Langerhans cell histiocytosis must be considered for RCC [4]. In our case, the radiographic image of mandibular lesion had a cystic lesion appearance. Such clear cell lesions in the jaw bone may resemble "xanthofibromas" and Langerhans cell histiocytoses. In this context, IHC panel consisting of S-100, CD1a, CD34, CD68 
and pan-CK was applied for differential diagnosis. Xanthofibroma and Langerhans cell histiocytosis were excluded, epithelial tumour metastasis was diagnosed positive immunoreactivity with pan$\mathrm{CK}$ and because of that, the pathology archive was scanned and the primary focus RCC was arrived.

Surgical removal, radiotherapychemotherapy and hormonal therapy can be used in the treatment of metastasis [4]. A comprehensive review suggests palliative treatment if the primary tumor spreads or if metastasis can not be removed by resection. Although clear-cell RCC is a radiotherapy-resistant tumor, radiotherapy may be useful in the treatment of metastatic disease. Chemotherapy is also useful in residual disease after resection, although the response is less than $25 \%$ [3]. However, due to the poor prognosis after enucleation and the involvement of $1 / 3^{\text {rd }}$ distal part of the right femur and $1 / 3^{\text {rd }}$ proximal part of the left tibia in our case, it was enough to wash the wound in the oral cavity with $250 \mathrm{mg} / \mathrm{ml}$ of rifamycin every other day for two weeks, according to the joint decision with the department of oncology.

\section{Conclusion}

The possibility of metastatic tumors should be considered in cases with excessive bleeding during operation, together with other clinical features.

Contributors: EA, IO, EYG: critical inputs into the manuscript, patient management; OFG: manuscript editing, histopathology; TCI: manuscript writing, patient management. TCI will act as guarantor. All authors approved the final version of this manuscript.

Funding: None; Competing interests: None stated.

\section{References}

1. Ferlay J, Shin HR, Bray F, Forman D, Mathers C, Parkin DM. Estimates of worldwide burden of cancer in 2008. Int J Cancer. 2010;127:2893-2917.
2. Yoskovitch A, Nguyen LH, Sadeghi N, Auger M. Renal cell carcinoma presenting as a mandibular mass. Otolaryngol Head Neck Surg. 2001;125:654-655.

3. Pritchyk KM, Schiff BA, Newkirk KA, Krowiak E, Deeb ZE. Metastatic renal cell carcinoma to the head and neck. Laryngoscope. 2002;112:1598-1602.

4. Kelles M, Akarcay M, Kizilay A, Samdanci E. Metastatic renal cell carcinoma to the condyle of the mandibula. $\mathrm{J}$ Craniofacial Surg. 2012;23(4):302-303.

5. Sachdeva K, Makhoul I, Javeed M, Curti. Renal cell carcinoma. eMed J. 2001;2:1-21.

6. Petersen RO. Urologic Pathology. 2nd ed. Philadelphia, JB: Lippincott Co; 1992:100-103.

7. Fletcher CD. In: Diagnostic histopathology of tumours. 2nd Ed. Vol. 1. Livingstone, Churchill. 2000:475-492.

8. Altınel D, Etit D, Tan A, Bayol Ü, Bulut V, Erdoğan IG, et al. Metastatic renal cell carcinoma initially presented as a tongue mass. Turk Patoloji Derg. 2010;26(3):261263.

9. Gupta K, Miller JD, Li JZ, Russell MW, Charbonneau C. Epidemiologic and socioeconomic burden of metastatic renal cell carcinoma ( $\mathrm{m} \mathrm{RCC}$ ). A literature review. Cancer Treat Rev. 2008;34(3):193-205.

10. Shome D, Honavar SG, Gupta P, Vemuganti GK, Reddy PV. Metastasis to the eye and orbit from renal cell carcinoma. A report of three cases and review of literature. Surv Ophthalmol. 2007;52(2):213-223.

11. Cheng ET, Greene D, Koch RJ. Metastatic renal cell carcinoma to the nose. Otolaryngol Head Neck Surg. 2000;122:464.

12. Bernstein JM, Montgomery WW, Balogh K Jr. Metastatic tumors to the maxilla, nose, and paranasal sinuses. Laryngoscope. 1966;76:621-650.

13. Hirshberg A, Leibovich P, Buchner A. Metastases to the oral mucosa: analysis of 157 cases. J Oral Pathol Med. 1993;22:385-390.

14. Rafla S. Renal cell carcinoma-natural history and results of treatment. Cancer. 1970;25:26-40.

15. Batsakis JG, McBurney TA. Metastatic neoplasms to the head and neck. Surg Gyn Obst. 1973;133:673-677. 